\title{
A ÉTICA EM MICHEL FOUCAULT: DO CUIDADO DE SI À ESTÉTICA DA EXISTÊNCIA
}

Ethics in Michel Foucault: From the self's care for aesthetics of existence

Bruno Abilio Galvão*

Resumo: A ética do "cuidado de si" consiste em um conjunto de regras de existência que o sujeito dá a si mesmo promovendo, segundo sua vontade e desejo, uma forma ou estilo de vida culminando em uma "estética da existência". O cuidado de si não consiste em uma ética em que o sujeito se isola do mundo, mas sim retorna para si mesmo para depois agir. Portanto, o objetivo do artigo é compreender e expor a concepção ética de Michel Foucault referente ao "cuidado de si" e sua culminância na vida compreendida como obra de arte denominada de "estética da existência". A metodologia utilizada é a de pesquisa bibliográfica pautada nos estudos de Foucault e de alguns estudiosos de seu pensamento que abordam o tema. A "estética da existência", que deriva de um processo de trabalho sobre si estabelecido pelo sujeito, é de fundamental importância de ser pensado, pois, ao constituir estilos diferenciados de vida, promove o surgimento de focos de resistência aos mecanismos de poder e dominação que têm como objetivo normalizar e padronizar os modos de vida dos sujeitos.

Palavras-chave: Cuidado de si. Estética da existência. Foucault. Subjetividade.

\begin{abstract}
The ethic of "self's care" consists of a set of rules of existence that the subject gives himself promoting, at his will and wish, one way or style of life culminating in a "aesthetics of existence". Self's care is not about ethics in which the subject is isolated from the world, but returns for yourself and then act. Therefore, the aim of the paper is to understand and expose the ethical conception of Michel Foucault refers to "self's care" and its culmination in life understood as a work of art called "aesthetics of existence". The methodology used is that search of literature guided the studies of Foucault and some scholars of his thought that address. The "aesthetics of existence", which derives from a work process in itself established on the subject, is of fundamental importance to be thought, therefore, to be differentiated lifestyles, promotes the emergence of pockets of resistance to the mechanisms of power and domination that aim to normalize and standardize the ways of life of the subjects.
\end{abstract}

Keywords: Self's care. Aesthetics of existence. Foucault. Subjectivity.

\footnotetext{
* Mestrando em Filosofia pela Universidade Federal do Espírito Santo (UFES). Contato: brunoabiliogalvao@hotmail.com
}

\begin{tabular}{|c|c|c|c|c|c|}
\hline intuitio & $\begin{array}{c}\text { ISSN } \\
1983-4012\end{array}$ & Porto Alegre & Vol.7- No.1 & $\begin{array}{c}\text { Junho } \\
2014\end{array}$ & p.157-168 \\
\hline
\end{tabular}




\section{Introdução}

De acordo com Deleuze ${ }^{1}$, o homem em relação a si, utilizando uma expressão de Heidegger, encontra-se "esquecido de seu esquecimento", o que, sobre a concepção ética de Foucault significa que ele se esquece de cuidar de si mesmo e, além disso, esquece-se desse esquecimento, o que o impede de "cuidar de si". Portanto, o homem, nessa condição, mantém-se distante de si com sua consciência localizada em outras coisas que não ele mesmo. Todavia, o homem necessita voltar para si para depois voltar-se para o mundo, caracterizando o duplo-retorno dessa concepção ética.

O termo heideggeriano "esquecimento do esquecimento" compartilhado por Deleuze para falar de Foucault, significa que o homem descuida de sua forma de viver ao adotar modelos de verdades padronizados e normativos com relação a $\mathrm{si}^{2}$. Portanto, a relação da atitude do homem para consigo é íntima com os modelos de verdade e, para Foucault ${ }^{3}$, uma mudança no paradigma filosófico sobre a verdade ocorrido no período da modernidade teria afastado o cuidado de si do pensamento filosófico.

Então, Foucault percebe que há a necessidade de se trazer novamente essa concepção ética de volta para a filosofia, pois, embora esta esteja afastada da filosofia, as práticas de si continuam existindo atreladas a outras coisas, o que dá forma à maneira como os indivíduos estabelecem a si mesmos seus modos de vida, culminando em uma "estética da existência" em que o homem, voltandose para si reflexivamente, alcança momentos de liberdade e dá a si mesmo regras de existência distintas de padrões e normas ditadas pelas relações sociais, esculpindo, assim como obra de arte, sua vida e subjetividade.

Portanto, o objetivo do artigo é compreender e expor a concepção ética de Michel Foucault referente ao "cuidado de si" e sua culminância na vida compreendida como obra de arte denominada de "estética da existência". O método utilizado será o de pesquisa bibliográfica pautada nos estudos de Foucault e de alguns estudiosos de seu pensamento que abordam o tema, tendo em vista que, conforme $\mathrm{Gil}^{4}$, a pesquisa bibliográfica é elaborada a partir de material já publicado. A importância do tema a ser desenvolvido se configura no fato de, ao se compreender a concepção ética de Foucault sobre a necessidade, tanto individual quanto política, do cuidado de si, as atitudes e pensamentos dos indivíduos possam ser direcionados a rumos distintos dos padrões e normas sociais, ou seja, que a vida não seja mais observada e compreendida sob a ótica mercadológica, mas sim sob a ótica da arte.

\footnotetext{
${ }^{1}$ DELEUZE, Gilles. Foucault. São Paulo: Brasiliense. 2005.

${ }^{2}$ PESSOA, Fernando Mendes. Entre pensar e ser, Heidegger e Parmênides. Anais de Filosofia Clássica, Rio de Janeiro, ano 1, vol.1, $\mathrm{n}^{\circ}$ 1, 2007. Disponível em <http://www.ifcs.ufrj.br/ afc/2007/pessoa.pdf $>$ Acesso em: 28/10/2013.

${ }^{3}$ FOUCAULT, Michel. A Hermenêutica do Sujeito. $2^{\mathrm{a}}$ ed. São Paulo: Martins Fontes. 2006.

${ }^{4}$ GIL, Antônio Carlos. Como elaborar projetos de pesquisa. São Paulo. Atlas. 1991.
}

\begin{tabular}{|c|c|l|l|l|l|}
\hline intuitio & $\begin{array}{c}\text { ISSN } \\
1983-4012\end{array}$ & Porto Alegre & Vol.7- $\mathrm{N}^{\mathrm{o}} .1$ & $\begin{array}{c}\text { Junho } \\
2014\end{array}$ & p.157-168 \\
\hline
\end{tabular}




\section{A localização e o distanciamento do homem em relação a si e seu duplo-retorno}

O "cuidado de si", de acordo com Foucault ${ }^{5}$, corresponde a uma ética em que o sujeito direciona suas atitudes sobre si mesmo, porém, não se trata de um egoísmo ou narcisismo, como será mostrado posteriormente, em que a relação do sujeito com o mundo e com o outro pouco importaria. Então, ao dizer que o cuidado de si se constitui como uma ação do sujeito para consigo mesmo, isto, diferenciando-se de um posicionamento egoísta e narcísico, implica, necessariamente, uma ação para com o outro. Portanto, podemos dizer que o "cuidado de si" se trata de um "duplo-retorno", primeiramente um "retorno para si" e, num segundo momento, um "retorno para o outro e para o mundo". Porém, esse "duplo-retorno" proporciona o aparecimento de uma questão de cunho ontológico, pois o sujeito, ao retornar para si, confronta-se com sua atual condição.

Num primeiro momento, supõe-se que o sujeito retorna para si porque, em um momento anterior, este se encontrava em outro lugar distinto de si. Portanto, que "outro lugar" é esse em que o sujeito habita, "fora de si", do qual deve retornar?

Sobre este lugar, para se estabelecer sua localização e sua distância, esse "fora de si" de que é necessário o retorno, não consiste em um mundo para além do sujeito no sentido platônico, mas sim em um estado de subjetividade no qual os sujeitos permanecem. Portanto, o retorno a si corresponde a uma mudança ou transformação da subjetividade. Então, o "cuidado de si", em sua primeira característica, se constitui como um retorno a si ou a saída de um estado subjetivo de "descuido de si" que consiste em não nos ocuparmos com nós mesmos, segundo Bolsoni ${ }^{6}$, o retorno a si mesmo, em uma de suas modalidades, corresponde ao trabalho da consciência sobre si mesma.

A respeito disso, de acordo com Platão ${ }^{7}$, Alcibíades, ao dialogar com Sócrates sobre seu desejo de governar a cidade, é persuadido por ele de que não dispunha de amadurecimento suficiente para tal. Pergunta então a Sócrates o que deve fazer para se aprimorar e Sócrates o responde que deve se ocupar consigo mesmo.

Sócrates - Como assim, Alcibíades? Não reconheces que cuidar de alguma coisa é fazer algo a seu respeito?

Alcibíades - Decerto

Sócrates - E sempre que o tratamento deixar essa coisa melhor do que era antes, não dizes que ela foi bem cuidada? ${ }^{8}$

\footnotetext{
${ }^{5}$ FOUCAULT, Michel. A Hermenêutica do Sujeito. $2^{\mathrm{a}}$ ed. São Paulo: Martins Fontes. 2006.

${ }^{6}$ BOLSONI. Betânia Vicensi. O cuidado de si e o corpo em Michel Foucault: perspectivas para uma educação corporal não instrumentalizadora. In: IX ANPEO SUL 2012: SEMINÁRIO DE PESQUISA EM EDUCAÇÃOO DA REGIÃO SUL, 2012, Caxias do Sul. Disponível em $<$ http://www.ucs.br/etc/conferencias/index.php/anpedsul/9anpedsul/paper/viewFile/1577/920>. Acesso em $10 / 12 / 2013$

${ }^{7}$ PLATÃo. Diálogos. Pará: Universidade Federal do Pará. 1975.

${ }^{8}$ PLATÃO. Diálogos. Pará: Universidade Federal do Pará. 1975. Pág. 236.
}

\begin{tabular}{|c|c|l|l|l|l|}
\hline intuitio & $\begin{array}{c}\text { ISSN } \\
1983-4012\end{array}$ & Porto Alegre & Vol.7- $\mathrm{N}^{\mathrm{o}} .1$ & $\begin{array}{c}\text { Junho } \\
2014\end{array}$ & p.157-168 \\
\hline
\end{tabular}


Nesse trecho, Sócrates, que se afirmava como um instrumento dos deuses e que tinha um papel a cumprir em Atenas incitando as pessoas sobre o cuidado de $\mathrm{si}^{9}$, diz a Alcibíades que cuidar de alguma coisa é fazer algo a seu respeito e que isto consiste em um aprimoramento daquilo que se cuida, tornando-a melhor. Portanto, o cuidado consiste em talhar ou lapidar algo retirando suas “imperfeições”, melhorando-a. Alcibíades, por meio de um cuidado para consigo, deve aprimorar-se para que seja capaz de exercer, da melhor forma possível, o governo da cidade. Porém Sócrates, percebendo Alcibíades ainda confuso, prossegue sua explicação dizendo que ocupar-se consigo difere de ocupar-se com objetos de nosso pertencimento. Sócrates utiliza vários exemplos para ilustrar isso, como o caso do sapateiro que, ao ocupar-se dos sapatos não se ocupa dos pés, ele torna melhor um aparato de conforto para os pés, porém não melhora o pé em si mesmo. Sócrates conclui então que "não é a arte por meio da qual deixamos melhor qualquer coisa que nos pertença, mas a que nos deixa melhores a nós mesmos" ${ }^{10}$. Portanto, o cuidado de si consiste na saída desta "localização" ou estado de subjetividade em que nos ocupamos com coisas que, mesmo próximas e que nos dizem respeito, não são nós mesmos.

Então, demarcado este espaço subjetivo, resta traçar o seu "distanciamento", ou seja, o quanto que a subjetividade se afasta de si ao travar e sofrer diversas interferências de variados processos de subjetivação, confundindo sua identidade ontológica com os padrões morais e normativos impostos como modos padronizados de vida. Portanto, há uma abstração idealizada da vida compreendida segundo regras de condutas às quais os sujeitos são direcionados afastando-se de si mesmos, ou seja, esquecem-se de si ao adotar um modelo padronizado de vida, ou , segundo Deleuze ${ }^{11}$, aproximando-se de Heidegger, os sujeitos esquecem que se encontram esquecidos. Porém, essa relação da qual Heidegger nos fala sobre o ente (sujeito) e o esquecimento do esquecimento de si é apenas um ponto de partida para Foucault, pois Heidegger esquece a dimensão investigada por Foucault a partir de Nietzsche, que é pensar o indivíduo como possibilidade de exercício de poder no sentido de "vontade de potência" 12 que, por meio da sua força vital desejante "dobra" a força que lhe é coextensiva e contrária constituindo um afeto em relação a si.

Portanto, duas sendas são abertas em relação ao cuidado de si, primeiro em relação ao "esquecimento do esquecimento" proposto por Heidegger que, segundo Deleuze ${ }^{13}$ é compartilhado por Foucault e, segundo, a questão do sujeito em relação ao exercício do poder, que lhe inflige um processo de subjetivação normativo produzindo esse esquecimento, provocando um embate ou confronto com o sujeito desejante no anseio de exercer sua particularidade enquanto modo de existência e os dispositivos de poder.

\footnotetext{
${ }^{9}$ PLATÃO. Apologia de Sócrates. Pará de Minas. Virtual Books Online M\&M Editores LTDA. 2003.

${ }^{10}$ PLATÃO. Diálogos. Pará: Universidade Federal do Pará. 1975. Pág. 237.

${ }^{11}$ DELEUZE, Gilles. Foucault. São Paulo: Brasiliense. 2005.

12 DELEUZE, Gilles. Foucault. São Paulo: Brasiliense. 2005. Pág. 121.

${ }^{13}$ DELEUZE, Gilles. Foucault. São Paulo: Brasiliense. 2005.
}

\begin{tabular}{|c|c|c|c|c|c|}
\hline intuitio & $\begin{array}{c}\text { ISSN } \\
1983-4012\end{array}$ & Porto Alegre & Vol.7 $-\mathrm{N}^{\circ} .1$ & $\begin{array}{c}\text { Junho } \\
2014\end{array}$ & p.157-168 \\
\hline
\end{tabular}




\section{0 cuidado de si e o esquecimento do esquecimento}

Deleuze $^{14}$, ao tratar do processo de subjetivação em Foucault, diz que o sujeito, enquanto imerso em relações de poder subjetivantes que tendem a normatizá-lo, afirma-se, em alguns casos, como ponto de resistência aos fluxos do poder configurando-se o "lado de fora" coextensivo aos diagramas de poder. O sujeito, assim, é o local onde a força é dobrada, porém, nesta dobra, o sujeito não permanece totalmente ileso, pois "resiste" enquanto foco de resistência e resistir significa ser afetado. Portanto, o diferencial nesta relação do sujeito que resiste e os fluxos do poder que lhe afetam se dá no quanto de si o sujeito retém.

Ainda, segundo Deleuze ${ }^{15}$, a "memória é o verdadeiro nome da relação consigo, ou do afeto de si por si”, portanto, na dobra, intercessão entre o poder coextensivo ao sujeito e a contra-força que este exerce, há uma tensão de forças. Por um lado, as maquinarias de poder forçam a dissolução do sujeito em seus diagramas e do outro há um sujeito que insiste em se afirmar, trata-se de uma tensão entre "memória" e "esquecimento", sendo a "memória" a auto-afecção do sujeito por si e o esquecimento a força contrária que tende ao descuido de si. Porém, esquecimento e memória coexistem na subjetividade do sujeito sendo o esquecimento constitutivo da memória, pois, embora o sujeito esteja ou permaneça em determinado momento, esquecido de si, imerso nos mecanismos de poder, este permanece atuando no espaço ao qual está situado e tais experiências proporcionam, à memória, enquanto subjetividade, refazer-se.

[...] enquanto o lado de fora está dobrado, um lado de dentro lhe é coextensivo, assim como a memória é coextensiva ao esquecimento. É esta co-extensividade que é a vida, longo período. O tempo se torna sujeito, por ser a dobra do lado de fora e, nessa condição, faz com que todo o presente passe ao esquecimento, mas conserva todo o passado na memória, o esquecimento como impossibilidade de retorno e a memória como necessidade de recomeçar ${ }^{16}$.

Embora haja entre memória e esquecimento um jogo de forças, estas não se opõem de maneira excludentes, mas sim coextensiva e constitutiva. Deleuze diz que esta luta ou jogo constitui a vida que sempre força por se refazer, porém, há o que ele chama de "morte do sujeito", em que a reinvenção de si cessa, ou seja, o sujeito vive esquecido de seu esquecimento. Portanto, a fim de compreender o aniquilamento do cuidado de si enquanto ética constitutiva do sujeito, é importante ver o que Heidegger diz sobre estar esquecido de seu esquecimento.

De acordo com Pessoa ${ }^{17}$, para Heidegger, a questão inicial colocada pelos gregos antigos, "o que é o ser?", teria sido desvirtuada de seu sentido originário tomando um rumo completamente

\footnotetext{
${ }^{14}$ DELEUZE, Gilles. Foucault. São Paulo: Brasiliense. 2005.

${ }^{15}$ DELEUZE, Gilles. Foucault. São Paulo: Brasiliense. 2005. Pág. 115.

${ }^{16}$ DELEUZE, Gilles. Foucault. São Paulo: Brasiliense. 2005. Pág. 115.

${ }^{17}$ PESSOA, Fernando Mendes. Entre pensar e ser, Heidegger e Parmênides. Anais de Filosofia Clássica, Rio de Janeiro, ano 1, vol.1, n 1, 2007. Disponível em 〈http://www.ifcs.ufrj.br/ afc/2007/pessoa.pdf > Acesso em: $28 / 10 / 2013$.
}

\begin{tabular}{|c|c|c|c|c|c|}
\hline intuitio & $\begin{array}{c}\text { ISSN } \\
1983-4012\end{array}$ & Porto Alegre & Vol.7 $-\mathrm{N}^{\circ} .1$ & $\begin{array}{c}\text { Junho } \\
2014\end{array}$ & p.157-168 \\
\hline
\end{tabular}


distinto de seu começo. O ser, durante toda a história da filosofia, teria sido pensado de maneira equivocada sendo compreendido como um ente, assim, em Platão este aparece como "ideia", em Kant como "razão", em Hegel como "espírito absoluto", em Nietzsche como "vontade de potencia", etc. A essa forma de pensar Heidegger chama de pensamento metafísico, o que teria acarretado o "obscurecimento do ser" que, consequentemente, promove seu esquecimento. Portanto, o ente, permanecendo no "esquecimento de seu esquecimento", não exerce e direciona seu pensamento para aquilo que Heidegger diz ser "o mais digno de ser pensado", o sentido do ser. Então, Heidegger incube-se da tarefa de retomar a questão do "ser" em seu sentido originário há muito abandonado na história da filosofia.

Porém, se Heidegger resgata a questão do ser e restabelece seu sentido originário de ser pensado, é necessário esclarecer o que é o "ser". Se tudo o que há no mundo, ou melhor, na physis, tudo o que surge e se mostra, são entes ${ }^{18}$, o que seria então o "ser"?

A diferença ontológica assinalada por Heidegger entre "ser" e "ente" consiste no fato de o ente corresponder a aquilo "que se efetua, tudo que é real e efetivo; ente é a realização do ser, o que é"19 e "ser" corresponde à "possibilidade de o ente aparecer - ele é o seu princípio original" ${ }^{20}$. Portanto, tudo o que é real e aparente, que se mostra, corresponde à esfera dos entes e, diferentemente, o "ser" ocupa a esfera da possibilidade de o ente vir-a-ser. Porém, o ser não corresponde a uma entidade aquém ou para além dos entes ou corresponderia ainda ao somatório desses, o ser, enquanto possibilidade de existência de cada ente oculta-se nestes na medida em que se mostram, ou seja, "o ser é a possibilidade do aparecer, que se oculta em todo ente que aparece - como vigor do possível, o ser se encobre no que se realiza" ${ }^{21}$.

Portanto, o esquecimento da verdade do ser diz respeito à "decadência" do pensamento nos "entes" tomando como verídico apenas o que se efetiva no aparecimento esquecendo a esfera da possibilidade desses aparecerem. Tal fato, para Heidegger, é decorrente da modernidade em que o homem passou a conceber a verdade como adequação correta entre juízo e coisa, portanto, verdade corresponde à certeza racional em que a representação das coisas descreve exatamente como elas são. Assim, o aparente passou a ter primazia sobre a possibilidade desencadeando uma compreensão da

\footnotetext{
${ }^{18}$ HEIDEGGER, Martin. Introdução à metafísica. $3^{\mathrm{a}}$ ed. Rio de Janeiro. Tempo brasileiro, 1987.

${ }^{19}$ PESSOA, Fernando Mendes. Entre pensar e ser, Heidegger e Parmênides. Anais de Filosofia Clássica, Rio de Janeiro, ano 1, vol.1, $\mathrm{n}^{\mathrm{o}}$ 1, 2007. Disponível em <http://www.ifcs.ufrj.br/ afc/2007/pessoa.pdf $>$ Acesso em: 28/10/2013. Pág. 77.

${ }^{20}$ PESSOA, Fernando Mendes. Entre pensar e ser, Heidegger e Parmênides. Anais de Filosofia Clássica, Rio de Janeiro, ano 1, vol.1, $\mathrm{n}^{\mathrm{o}}$ 1, 2007. Disponível em <http://www.ifcs.ufrj.br/ afc/2007/pessoa.pdf $>$ Acesso em: 28/10/2013. Pág. 77.

${ }^{21}$ PESSOA, Fernando Mendes. Entre pensar e ser, Heidegger e Parmênides. Anais de Filosofia Clássica, Rio de Janeiro, ano 1, vol.1, $\mathrm{n}^{\mathrm{o}}$ 1, 2007. Disponível em <http://www.ifcs.ufrj.br/ afc/2007/pessoa.pdf > Acesso em: 28/10/2013. Pág. 77.
}

\begin{tabular}{|c|c|l|l|l|l|}
\hline intuitio & $\begin{array}{c}\text { ISSN } \\
1983-4012\end{array}$ & Porto Alegre & Vol.7 $-\mathrm{N}^{\circ} .1$ & $\begin{array}{c}\text { Junho } \\
2014\end{array}$ & p.157-168 \\
\hline
\end{tabular}


essência dos entes como "substância" permanente e imutável, desqualificando o horizonte de possibilidades dos entes ${ }^{22}$.

Mediante a esse anseio por apreender o real em sua verdade pelo aparente, diversas técnicas de observação e vigilância surgem neste período proporcionando uma série de arquivos a respeito do homem, objetivando a construção de verdades a respeito deste. O homem é conceituado como um objeto ou coisa passível de sua própria análise e investigação. Temos então, durante a modernidade, a apreensão do sujeito em representações conceituais delimitando e dizendo o que ele é e, consequentemente, o modo e a possibilidade única de ele ser. Assim, a abertura ontológica do horizonte de possibilidades que cabe aos entes virem-a-ser é jogada para o esquecimento sendo a eles apontados outros direcionamentos, por meio de táticas de exercício de poder atrelados a construções de verdades sobre o homem, conduzindo-os a uma subjetividade dócil.

Foucault ${ }^{23}$ nos fala que nesse período houve uma supervalorização do conhecimento de si em detrimento do "cuidado de si", o que ele chama de "momento cartesiano". Nesse período, em que há uma reviravolta no paradigma em relação ao "o que é a verdade" traz um grande problema para o homem em relação ao afastamento de si mesmo, pois por um lado, se tratando de Heidegger, temos o esquecimento do ser em que os entes adotam, esquecendo-se de sua possibilidade de vir-a-ser, uma existência meramente cotidiana, no sentido ôntico de que "nem sempre este si se desvela como um si mesmo propriamente em sua cotidianidade" ${ }^{24}$ e por outro, se tratando de Foucault, os sujeitos ocupam-se, ao serem enquadrados em normas e padrões de vida, com coisas distintas de si mesmos.

Mas, o que muda então em relação à verdade para que o cuidado de si tenha sido encoberto e esquecido em detrimento do conhecimento de si e, estendendo um pouco mais a questão, se houve uma desqualificação do "cuidado de si" no período da modernidade, este, então, antecedendo a este momento, possuía importância considerável em relação ao conhecimento? E, mais ainda, por que este tema é resgatado e recolocado por Foucault?

\section{Da espiritualidade e a ascensão à verdade ao conhecimento moderno}

Na modernidade, a "verdade" tem sua fonte na evidência, por exemplo, Descartes ${ }^{25}$ elucida um princípio indubitável pela via racional e alcança um princípio sobre si mesmo de validade universal, inicia-se assim a construção conceitual do homem enquanto objeto de conhecimento, este se insere em

\footnotetext{
${ }^{22}$ PESSOA, Fernando Mendes. Entre pensar e ser, Heidegger e Parmênides. Anais de Filosofia Clássica, Rio de Janeiro, ano 1, vol.1, $\mathrm{n}^{\circ} 1$, 2007. Disponível em <http://www.ifcs.ufrj.br/ afc/2007/pessoa.pdf $>$ Acesso em: 28/10/2013.

${ }^{23}$ FOUCAULT, Michel. A Hermenêutica do Sujeito. 2. ed. São Paulo: Martins Fontes. 2006.

${ }^{24}$ COSTA, Denise Magalhães da. O Si - Mesmo e a Singularidade da Presença. 2007. Dissertação (Mestrado em Filosofia). Faculdade de Filosofia e Ciências Humanas, Universidade Federal da Bahia, Salvador, 2007. Disponível em <WWW.ppgf.ufba.br/dissertacoes/denise_magalhaes.pdf $>$ acesso em 13/08/2013. Pág. 32.
}

${ }^{25}$ DESCARTES, René. Meditações. São Paulo: Martin Claret. 2008

\begin{tabular}{|c|c|l|l|l|l|}
\hline intuitio & $\begin{array}{c}\text { ISSN } \\
1983-4012\end{array}$ & Porto Alegre & Vol.7- $\mathrm{N}^{\mathrm{o}} .1$ & $\begin{array}{c}\text { Junho } \\
2014\end{array}$ & p.157-168 \\
\hline
\end{tabular}


um processo de formação conceitual de si mesmo. Busca-se então ilustrar o homem, representá-lo conceitualmente, o sujeito de conhecimento, buscando formas universais, pergunta-se "o que é o homem?" e não mais "quem sou eu?", ou seja, o conhecimento de si é deslocado para uma representação de si mesmo presa a um universal, portanto, o objeto de investigação é o homem cujo objetivo é traçar a figura de um "eu" universal. Portanto, o método moderno para saber "quem eu sou", desvincula-se de toda forma de relação de cuidado para consigo, pois, para ter acesso à verdade sobre si, basta conhecer toda a formação discursiva a respeito do homem.

Uma vez que, na modernidade, o "cuidado de si" é banido do pensamento filosófico em detrimento do conhecimento de si, pois esse, por si só é suficiente para acessar a verdade, a relação entre o cuidado de si e o conhecimento referente ao período filosófico precedente à modernidade é caracterizado por Foucault como "espiritualidade", que se traduz como:

[...] o conjunto de buscas, práticas e experiências tais como as purificações, as asceses, as renúncias, as conversões do olhar, as modificações de existência, etc., que constituem, não para o conhecimento, mas para o ser mesmo do sujeito, o preço a pagar para ter acesso à verdade ${ }^{26}$.

Portanto, a espiritualidade consiste num conjunto de atitudes as quais o sujeito exerce sobre si mesmo para ter acesso à verdade. A "verdade", nesse sentido, distinta da "evidência" moderna, exige do sujeito, pois por ela se "paga um preço", um olhar apurado sobre si mesmo, um exame das atitudes e do modo como ele vive no mundo, ou seja, para ter acesso a verdade é necessário "modificar a forma de existir", no sentido de se "purificar", ou seja, abandonar ou renunciar o que mancha ou faz decair o caráter do sujeito. Para ter acesso à verdade, deve-se cuidar da própria existência no sentido de tornála melhor, uma vez que purificar se traduz num movimento hierárquico do menos elevado para o mais elevado, é necessário enaltecer a vida se livrando de tudo o que a faz degradar. Assim, a espiritualidade "postula a necessidade de que o sujeito se modifique, se transforme, se desloque [...]"27, pois "a verdade só é dada ao sujeito a um preço que põe em jogo o ser mesmo do sujeito"28.

A espiritualidade postula que o sujeito deva "converter-se" a si mesmo e também "trabalhar" sobre si. Portanto, "conversão" e "trabalho" formam um par de atitudes com as quais o homem deve haver-se para ter acesso à verdade. Convertendo-se a si, o sujeito é arrancado de seu status atual na medida em que a "verdade" vem sobre ele e o ilumina. Consciente de si e de suas verdades, este indivíduo guia suas atitudes de maneira diferenciada de sua condição anterior, portanto, ascender à verdade exige do sujeito um trabalho sobre si objetivando sua transformação.

A "espiritualidade" nunca esteve separada da aquisição do conhecimento, diferentemente na modernidade, em que a aquisição da verdade ocorre unicamente pela via do conhecimento desvinculado do cuidado consigo que o indivíduo deve manter. Portanto, nessa época, com a mudança de paradigmas filosóficos acerca do que é a verdade, um modo de vida pautado no cuidado para

${ }^{26}$ FOUCAULT, Michel. A Hermenêutica do Sujeito. $2^{\text {a }}$ ed. São Paulo: Martins Fontes. 2006. Pág. 19.

${ }^{27}$ FOUCAULT, Michel. A Hermenêutica do Sujeito. $2^{\mathrm{a}}$ ed. São Paulo: Martins Fontes. 2006. Pág. 19 - 20.

${ }^{28}$ FOUCAULT, Michel. A Hermenêutica do Sujeito. $2^{\mathrm{a}}$ ed. São Paulo: Martins Fontes. 2006. Pág. 20.

\begin{tabular}{|c|c|c|c|c|c|}
\hline intuitio & $\begin{array}{c}\text { ISSN } \\
1983-4012\end{array}$ & Porto Alegre & Vol.7- $\mathrm{N}^{\mathrm{o}} .1$ & $\begin{array}{l}\text { Junho } \\
2014\end{array}$ & p.157-168 \\
\hline
\end{tabular}


consigo se torna descartável em relação ao alcance da verdade, então, na história da filosofia, a partir deste momento, o cuidado de si se desvincula do conhecimento, pois o homem, sem a necessidade de transformar a si mesmo, é capaz de verdade.

Porém, embora a prática do "cuidado de si" tenha perdido sua posição junto ao conhecimento, tal prática não caiu na inexistência, embora alguns indivíduos encontrem-se esquecidos de si. Para algumas comunidades religiosas ainda permanece associado, fortemente, com o acesso à verdade, para outras pessoas, desvinculadas de movimentos espiritualistas e escolas filosóficas, o cuidado de si ocorre, enquanto prática de vida, desvinculado de qualquer forma de acesso à verdade. Porém, qual o interesse de Foucault em resgatar o cuidado de si e reinseri-lo e pensá-lo filosoficamente?

\section{Foucault e a necessidade de uma ética voltada para si}

O pensamento de Foucault é divido em três momentos que se intercalam e se intercruzam entre si, cada estágio de sua filosofia é o aprofundamento do outro, como se Foucault fosse escavando mais e mais o terreno de sua investigação. O primeiro momento é compreendido como o período "arqueológico" em que o objeto de análise é o saber, ele investiga os jogos de verdades e as regras que compõem as formações discursivas que proporcionam o aparecimento de determinado saber. No segundo momento de sua filosofia, "genealógico", inicia-se pelo fato de que, ao estudar as condições de verdade, percebe que sua produção e seu surgimento estão associados a determinadas práticas sociais, sendo uma das regras às quais a produção discursiva mantém em sua raiz. Portanto, nesse momento, Foucault descobre que essas práticas sociais relacionadas à produção do saber ocorrem mediadas por "relações de poder". Trata-se de um momento em que as práticas estabelecidas entre os sujeitos se tornam objeto de análise e, ao observar as relações estabelecidas entre poder e saber, ele descobre uma série de mecanismos e estratégias que promovem determinado tipo de relações entre eles. Dessa forma, as estratégias de poder visam a controlar as atitudes dos indivíduos, a governar suas ações. Os indivíduos submetidos a este regime de relações tem sua subjetividade moldada. Com esse objetivo, criam-se estratégias de exercício de poder direcionadas em produzir uma espécie de subjetividade, o que configura na construção do sujeito dócil, ou seja, corpo eficiente em termos de produção e incapaz de problematizar e reagir ao sistema ${ }^{29}$. Foucault, então, descobre os dispositivos de poder, instituições que encerram em seu interior todo um funcionamento gerenciado por diversas modalidades de exercício do poder e percebe que tais instituições produtoras de subjetividade acompanham o ser humano desde o nascimento ao momento de sua morte.

Porém, no terceiro momento, Foucault percebe falhas nessa estrutura moldada por estratégias de poder, há pontos no diagrama de poder que oferecem resistência, ou seja, dobram o poder ${ }^{30}$, escapam, em parte, do processo de docilização. Há uma luta, uma tensão entre forças, de um lado o

${ }^{29}$ FOUCAULT, Michel. Vigiar e Punir. Rio de Janeiro. Vozes. 2007.

${ }^{30}$ DELEUZE, Gilles. Foucault. São Paulo: Brasiliense. 2005.

\begin{tabular}{|c|c|l|l|l|l|}
\hline intuitio & $\begin{array}{c}\text { ISSN } \\
1983-4012\end{array}$ & Porto Alegre & Vol.7- $\mathrm{N}^{\mathrm{o}} .1$ & $\begin{array}{l}\text { Junho } \\
2014\end{array}$ & p.157-168 \\
\hline
\end{tabular}


indivíduo que quer dar vazão ao seu desejo vivendo a sua maneira, do outro, uma série de dispositivos que tentam dobrar os indivíduos e controlar sua subjetividade e desejo. Assim, alguns indivíduos escapam parcialmente, pois, para Foucault, é impossível viver fora das relações de poder e manter, constantemente, a "lembrança de si", que do lado de fora dos mecanismos de poder, em sua subjetividade, clama por vir a ser assim como o indivíduo é, cuidando da sua forma de existir, de fazer de sua vida, além dos momentos de confronto, aquilo que de fato deseja manter. Trata-se de cultivar o "si" e desviar das artimanhas do poder sem cair no esquecimento.

Dessa forma, o sujeito é compreendido por Foucault como um "eu" ético em relação consigo mesmo, sendo assim compreendido como "transformável, modificável: é um sujeito que se constrói, que se dá regras de existência e conduta [...]"31. A ética consiste, para Foucault, no direcionamento da própria subjetividade reflexiva para si visando formas de se reinventar, de se elaborar a própria vida.

Porém, segundo Gros ${ }^{32}$, Foucault é acusado de defender uma ética que separa o indivíduo do mundo, como se este pouco se importasse com os acontecimentos circundantes, fechando-se em si mesmo num puro narcisismo, mas ele explica que a ética de Foucault se direciona por uma via oposta a essa. O sujeito cria uma "distância" entre si e o mundo não egoisticamente, mas sim, criando essa distância, volta-se para si, para agir sobre o mundo. Trata-se de um "eu" reflexivo que, de acordo com as circunstâncias, recolhe-se para depois agir. Como exemplo disso, Gros ${ }^{33}$ narra um fato grego em que um pai de família, ao retornar para casa, percebe sua filha doente e foge da situação e Epíteto, ao procurá-lo, encontra-o e lhe diz:

Se você fugiu das tuas responsabilidades é porque você não cuidou direito de si mesmo; você se preocupou demais com sua filha e se impressionou demais com a doença, enquanto que se você tivesse introduzido entre você e o mundo uma certa distância, uma certa defasagem, você poderia retomar a si mesmo, preocupar-se consigo mesmo, dizendo: "o que está acontecendo, a doença de minha filha exige de mim um certo papel a desempenhar: o do pai de família, e este papel impõe um certo número de deveres como proteção, o cuidado dos seus, etc.”.

Portanto, a proposta de Foucault consiste em cuidar de si para poder cuidar do outro, exigindo responsabilidades para com o mundo, o que não significa que hajam regras de conduta préestabelecidas sobre como se deva agir, o que não deve ser confundido com a ética foucaultiana, que trata da própria avaliação do sujeito ante as circunstâncias para assim dar a si suas próprias maneiras de ações.

\section{A estética da existência}

${ }^{31}$ GROS, Frédéric. O Cuidado de Si em Michel Foucault. In: RAGO, Margareth (Org.); VEIGA-NETO, Alfredo (Org.). Figuras de Foucault. $2^{\text {a }}$ ed. Belo Horizonte: Autêntica. 2008. Pág. 128.

${ }^{32}$ GROS, Frédéric. O Cuidado de Si em Michel Foucault. In: RAGO, Margareth (Org.); VEIGA-NETO, Alfredo (Org.). Figuras de Foucault. $2^{\mathrm{a}}$ ed. Belo Horizonte: Autêntica. 2008.

${ }^{33}$ GROS, Frédéric. O Cuidado de Si em Michel Foucault. In: RAGO, Margareth (Org.); VEIGA-NETO, Alfredo (Org.). Figuras de Foucault. $2^{\text {a }}$ ed. Belo Horizonte: Autêntica. 2008. Pág. 132.

\begin{tabular}{|c|c|l|l|l|l|}
\hline intuitio & $\begin{array}{c}\text { ISSN } \\
1983-4012\end{array}$ & Porto Alegre & Vol.7- $\mathrm{N}^{\mathrm{o}} .1$ & $\begin{array}{c}\text { Junho } \\
2014\end{array}$ & p.157-168 \\
\hline
\end{tabular}


Foi mostrado até agora o que Foucault compreende como ética fundada na noção de "cuidado de si”, porém, resta ainda compreender ou pelo menos demarcar onde esta prática culminará. Segundo Silva $^{34}$, as práticas de si têm como objetivo, consciente ou inconsciente, se assim pode ser dito, pois nem todos os indivíduos partilham da mesma leitura da realidade, alcançar momentos de "liberdade". É utilizada a expressão "momentos de liberdade", pois não se trata de um patamar da vida pleno e transcendental, pensar sobre a liberdade implica num retorno aos diversos tipos e modalidades simbólicas de prisão. Portanto, o "si" do sujeito encontrar-se-ia em diversas prisões simbólicas as quais o impedem de fazer de sua vida um alinhamento com sua vontade. Então, cuidar de si é alcançar cumes de liberdade para agir, e essas atitudes, escolhas e formas de pensamento subjetivam o sujeito de forma distinta do projeto dócil de subjetividade moderna.

Qual é, então, a prisão do homem moderno? O homem moderno encontra-se aprisionado em seu próprio "humanismo", conceito ao qual construiu para a universalidade de "si" e enquadrou toda sua espécie nesse "pacote". O humanismo, conceito moderno que delimita o homem em sua compreensão de si, forjado por diversos jogos de poder e saber, veda ao homem outras possibilidades de liberdade, direcionado-o a um modelo universal normalizante. Portanto, a partir da conquista desses "momentos de liberdade", o sujeito passa a construir e a elaborar outros modelos de vida distintos na medida em que vai se apropriando de si e modificando a própria vida, trata-se de conceber esta como obra de arte a ser realizada, de tomar seus próprios direcionamentos e atitudes, esculpindo, assim, sua própria subjetividade na medida em que vai produzindo seu próprio estilo de vida.

Portanto, vida, para Foucault, é compreendida como obra de arte a se fazer, afirmando que, cada um selecionando para si, a sua maneira, regras de existência, constitua sua vida de maneira agradável aos seus próprios olhos.

Antes de ser algo restrito apenas a produção do belo nas belas artes, obra de arte é o modo de ser de toda e qualquer produção original, no sentido da criação que faz aparecer o que, antes, não aparecia, [...]. Arte é fazer aparecer, mostrar- essa é a sua obra, a criação $0^{35}$.

Então, a estética da existência, consequência do cuidado de si, corresponde ao fato de cada um, uma vez que arte é fazer aparecer, trazer à luz, expressar seu originário modo de existência, o que só pode ser concretizado mediante uma obra, um trabalho sobre si mesmo.

\section{Conclusão}

\footnotetext{
${ }^{34}$ SILVA, Stela Maris da. A vida como obra de arte. Revista Científica FAP, Curitiba, ano2, vol. 2, janeiro dezembro 2007. Disponível em: < http://www.fap.pr.gov.br/arquivos/File/RevistaCientifica2/stelamaris.pdf > Acesso em 27/10/2013.

${ }^{35}$ PESSOA, Fernando. A vida como obra de arte. S/D. disponível em <http://secult.es.gov.br/_midias/pdf/22234a64ac4b80cc9.pdf>. Acesso em 10/12/2013.
}

\begin{tabular}{|c|c|c|c|c|c|}
\hline intuitio & $\begin{array}{c}\text { ISSN } \\
1983-4012\end{array}$ & Porto Alegre & Vol.7- $\mathrm{N}^{\circ} .1$ & $\begin{array}{l}\text { Junho } \\
2014\end{array}$ & p.157-168 \\
\hline
\end{tabular}


Após essa exposição, compreende-se que para Foucault, o cuidado de si corresponde a uma postura ética diante do mundo em que o indivíduo, antes de agir sobre este, volta-se para si reflexivamente, agindo sobre si e depois sobre o mundo. A atitude para consigo corresponde a um cuidado com a própria vida tanto em seu sentido biológico quanto subjetivo, ou seja, o homem, num embate com padrões de existência normalizantes, movido por sua vontade de vir a ser algo que esteja de acordo com seu desejo de vida, molda sua subjetividade através de suas escolhas.

Moldar a vida segundo a vontade própria, configura-se num processo de transformação do sujeito em que este busca "purificar-se", ou seja, abandonar tudo o que torna a vida como algo meramente ordinário e cotidiano como um horizonte fechado para uma única possibilidade. Então o homem, amarrado e aprisionado em diversas prisões simbólicas e subjetivas, entra em confronto com forças externas que tentam lhe dobrar e lhe tornar dócil, lapidando e esculpindo sua vida como obra de arte a ser feita e refeita a cada instante.

Então, conclui-se que a ética do cuidado de si, enquanto atitudes do sujeito para consigo mesmo, constitui-se em um conjunto de práticas e regras de existência que o sujeito dá a si e esse cuidado para consigo, transformando suas atitudes e sua subjetividade, torna a vida, metaforicamente falando, "bela", culminando na compreensão desta como "estética da existência".

\section{Referências}

BOLSONI. Betânia Vicensi. O cuidado de si e o corpo em Michel Foucault: perspectivas para uma educação corporal não instrumentalizadora. In: IX ANPEO SUL 2012: SEMINÁRIO DE PESQUISA EM EDUCAÇÃ̃O DA REGIÃO SUL, 2012, Caxias do Sul. Disponível em $\langle$ http://www.ucs.br/etc/conferencias/index.php/anpedsul/9anpedsul/paper/viewFile/1577/920>. Acesso em $10 / 12 / 2013$.

COSTA, Denise Magalhães da. O Si - Mesmo e a Singularidade da Presença. 2007. Dissertação (Mestrado em Filosofia). Faculdade de Filosofia e Ciências Humanas, Universidade Federal da Bahia, Salvador, 2007. Disponível em <WWW.ppgf.ufba.br/dissertacoes/denise_magalhaes.pdf $>$ acesso em 13/08/2013.

DELEUZE, Gilles. Foucault. São Paulo: Brasiliense. 2005.

DESCARTES, René. Meditações. São Paulo: Martin Claret. 2008

FOUCAULT, Michel. A Hermenêutica do Sujeito. $2^{\mathrm{a}}$ ed. São Paulo: Martins Fontes. 2006.

FOUCAULT, Michel. Vigiar e Punir. Rio de Janeiro. Vozes. 2007.

GIL, Antônio Carlos. Como elaborar projetos de pesquisa. São Paulo. Atlas. 1991.

GROS, Frédéric. O Cuidado de Si em Michel Foucault. In: RAGO, Margareth (Org.); VEIGA-NETO, Alfredo (Org.). Figuras de Foucault. $2^{\mathrm{a}}$ ed. Belo Horizonte: Autêntica. 2008.

HEIDEGGER, Martim. Introdução à metafísica. $3^{\text {a }}$ ed. Rio de Janeiro. Tempo brasileiro, 1987.

PESSOA, Fernando. A vida como obra de arte. S/D. disponível em $<<$ http://secult.es.gov.br/_midias/pdf/22234a64ac4b80cc9.pdf $>$. Acesso em 10/12/2013.

PESSOA, Fernando Mendes. Entre pensar e ser, Heidegger e Parmênides. Anais de Filosofia Clássica, Rio de Janeiro, ano 1, vol.1, no 1, 2007. Disponível em <http://www.ifcs.ufrj.br/ afc/2007/pessoa.pdf $>$ Acesso em: 28/10/2013.

PLATÃO. Diálogos. Pará: Universidade Federal do Pará. 1975.

PLATÃO. Apologia de Sócrates. Pará de Minas. Virtual Books Online M\&M Editores LTDA. 2003

SILVA, Stela Maris da. A vida como obra de arte. Revista Científica FAP, Curitiba, ano2, vol. 2, janeiro dezembro 2007. Disponível em: 〈 http://www.fap.pr.gov.br/arquivos/File/RevistaCientifica2/stelamaris.pdf > Acesso em 27/10/2013.

Recebido em: 18/04/2014

Aprovado para publicação em: 08/05/2014

\begin{tabular}{|c|c|l|l|l|l|}
\hline intuitio & $\begin{array}{c}\text { ISSN } \\
1983-4012\end{array}$ & Porto Alegre & Vol.7 $-\mathrm{N}^{\circ} .1$ & $\begin{array}{c}\text { Junho } \\
2014\end{array}$ & p.157-168 \\
\hline
\end{tabular}

